\title{
Numerical Modeling of the Effects of Electrode Spacing and Multilayered Concrete Resistivity on the Apparent Resistivity Measured Using Wenner Method
}

\author{
Karthick Thiyagarajan ${ }^{1}$, Parikshit Acharya ${ }^{2}$, Lasitha Piyathilaka ${ }^{3}$, Sarath Kodagoda ${ }^{4}$ \\ iPipes Lab, UTS Robotics Institute, Faculty of Engineering and Information Technology \\ University of Technology Sydney \\ Sydney, Australia

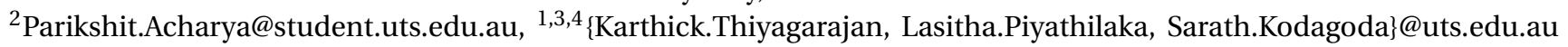

\begin{abstract}
Smart Sensing technologies can play an important role in the conditional assessment of concrete sewer pipe linings. In the long-term, the permeation of acids can deteriorate the pipe linings. Currently, there are no proven sensors available to non-invasively estimate the depth of acid permeation in real-time. The electrical resistivity measurement on the surface of the linings can indicate the sub-surface acid moisture conditions. In this study, we consider acid permeated linings as a two resistivity layer concrete sample, where the top resistivity layer is assumed to be acid permeated and the bottom resistivity layer indicates normal moisture conditions. Firstly, we modeled the sensor based on the four-probe Wenner method. The measurements of the developed model were compared with the previous studies for validation. Then, the sensor model was utilized to study the effects of electrode contact area, electrode spacing distance and two resistivity layered concrete on the apparent resistivity measurements. All the simulations were carried out by varying the thickness of top resistivity layer concrete. The simulation study indicated that the electrode contact area has very minimal effects on apparent resistivity measurements. Also, an increase in apparent resistivity measurements was observed when there is an increase in the distance of the electrode spacing. Further, a machine learning approach using Gaussian process regression modeling was formulated to estimate the depth of acid permeated layer.

Index Terms-Apparent resistivity, acid permeation, concrete, corrosion, electrode spacing, electrical resistivity, four probe, Gaussian process, multilayered concrete resistivity, numerical modeling, pipe linings, sensor, sewer, Wenner method.
\end{abstract}

\section{INTRODUCTION}

Structural health monitoring is an essential aspect for assessing the conditions of ageing civil infrastructures like underground concrete sewer pipes. The majority of those pipes are affected by concrete corrosion, which is more often attributed to sulfate-reducing bacterial activities that happen on the walls of concrete sewer pipes [1]. As a result, sulphuric acid is produced and penetrates the cementitious material of the pipe [2]. Water utilities spend millions of

This research was supported by the Cooperative Research Centres Project (CRC-P) on Smart Linings for Pipes and Infrastructure.

Corresponding Author: Karthick Thiyagarajan dollars each year to address corrosion-related pipe deterioration and rehabilitation [3]. Failure to prevent corrosion can lead to a structural breakdown, which largely incurs the financial cost and severely affects public health and the environment [4].

Currently, there are no sensing technologies available to directly measure the rate of corrosion or penetration of acids into the concrete material. Most water utilities, take core samples at discrete locations of the pipe to determine the rate of corrosion [5]. This process involves human traverses for taking core samples followed by $\mathrm{pH}$ tests in the laboratory. A major water utility in Australia has developed a predictive analytics model for estimating the corrosion throughout the sewer network [6]. The developed model requires hydrogen sulphide $\left(\mathrm{H}_{2} \mathrm{~S}\right)$ content in sewer atmosphere, surface temperature and surface moisture conditions as data inputs for predictions. There is a commercially available system for monitoring $\mathrm{H}_{2} \mathrm{~S}$ in sewer gas [7]. A sensing suite was recently developed for monitoring surface temperature [8], [9] and surface moisture conditions [10], [11]. Those sensors are capable of monitoring for a longterm period. However, they can produce anomaly or fail because of adverse environmental conditions [12], [13]. This will hamper the corrosion monitoring process. Another method of estimating sewer corrosion is by estimating the amount of intact concrete cover to the reinforcement bar (rebar) through multiple sensors. This method work by localizing the rebar using ground penetrating radar [14], capacitive sensor [15] or electrical resistivity based sensors [16], [17]. Then, estimating the depth of located rebar through pulsed eddy current sensing method [18] combined with drill resistance sensing system for measuring the thickness of the corroded concrete layer [19]. With the information from multiple sensors, corrosion is estimated.

Replacement of corroded sewer pipes is expensive [20]. To minimize rehabilitation costs, water utilities utilize pipe lining technology. The linings are the protective coatings applied to the deteriorated host structure to increase the 
structural integrity and reduce the effects of corrosion. In general, sewer pipe linings can be made up of calcium aluminate cement or geopolymer based materials. They offer high resistance to the sulphuric acid generated on the walls of the concrete sewer pipes. However, the linings can deteriorate in the long-term due to the permeation of acids. Hence, monitoring sewer pipe linings in the longterm is vital for water utilities. Reliable sensing technologies can provide information about the long-term performance of the linings. However, as mentioned earlier, there are no sensing systems or methods to non-invasively estimate the permeation or penetration of acids inside the concrete sewer pipe. The larger picture of this research work is to develop a non-invasive sensing technology that can provide information on acid permeation in linings. The thickness of the sewer pipe linings on the top of the host concrete pipe is $2 \mathrm{~cm}$. We have identified an electrical resistivity based sensing method as a prime candidate that can provide information about the depth of the acid permeation. Characterization of the sensing method through numerical simulations can provide insights about the sensor behaviour. In this context, this paper focuses on numerical characterization to study the sensing effects. The contributions of this paper are: (a) a sensor model was developed based on the Wenner method for apparent resistivity measurements. The model was evaluated with previous studies to utilize for the proposed application reported in this work, (b) studied the effects of electrode contact area and two-layered concrete resistivity on apparent resistivity measurements, (c) the effects of electrode spacing and two-layered concrete resistivity on apparent resistivity measurements were studied and (d) a machine learning approach using Gaussian process modeling was formulated to estimate the depth of acid permeated layer.

The rest of this paper is organised as follows: Section II reviews the related work. Section III describes the adopted methodology for apparent resistivity measurements and simulations followed by results in Section IV. Finally, Section $\mathrm{V}$ concludes the paper with future work.

\section{BRIEF REVIEW OF RELATED WORK}

The electrical resistivity measurement of concrete using four probes is a popular non-invasive technique. Based on the arrangement of the probes, the sensing technique can be classified into several methods [21], which include the Wenner method, Dipole-dipole method, Schlumberger method, Pole-pole method, Pole-dipole method, Double Wenner method, Half Schlumberger method, and Cross borehole method. Among different probe sensing method, the Wenner method was used for measuring electrical resistivity on the surface of the multi-layered resistivity concrete [22], [23]. A large concrete sample having $30 \mathrm{~cm}$ (length) $\times 30 \mathrm{~cm}$ (breadth) $\times 15 \mathrm{~cm}$ (height) was utilized to study the effects of multi-layered resistivity concrete on surface resistivity measurements [24]. The dimension of the concrete used in that study is large in the context of our

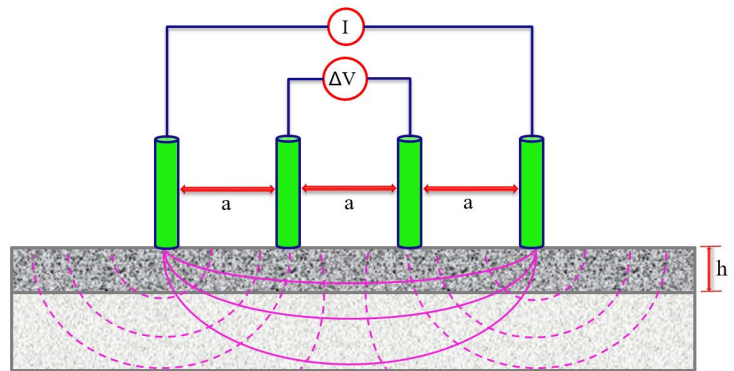

Fig. 1: Illustration of Wenner method.

application. Based on our literature review, we have not found literature that reports the effects of multi-layered resistivity concrete having a maximum $2 \mathrm{~cm}$ thickness on the resistivity measurements. The $2 \mathrm{~cm}$ thickness relates to the thickness of the sewer pipe linings.

An analytical model was developed [24] to determine the resistivity in the two resistivity layered concrete by using a technique that determines the earth's resistance by solving the Laplace equation on a semi-infinite medium [25]. However, the analytical model performed well when the thickness of the concrete is more than $7.5 \mathrm{~cm}$. There are few data-driven machine learning models [26], [27] developed for estimating concrete properties by using resistivity as input data. Those models entirely rely on the quality of training dataset and subjected to high uncertainties.

In this work, we employ the Wenner method for determining the surface resistivity measurements. The next section describes the sensing principle of the Wenner method.

\section{Methodology}

\section{A. Sensing Principle and Modeling}

The resistivity of the concrete samples can be noninvasively measured through the Wenner method. This method consists of four probes (electrodes). The electrodes are equally spaced and they are in contact with the surface of the concrete. A current signal $(I)$ is applied in the outer two electrodes. The inner two electrodes measure the potential difference $(\Delta V)$. The apparent resistivity $\rho_{a}$ is computed by using equation (1).

$$
\rho_{a}=2 \pi a \frac{\Delta V}{I}
$$

where $2 \pi$ is the geometric correction factor. In this work, we used alternating current with 40 Hertz frequency as an input signal. Figure 1 illustrates the Wenner method. The term $a$ refer to the distance between the electrode spacing and $h$ refers to the thickness of the top resistivity layer (wet layer). For a more detailed background on the Wenner method, the readers can refer to [28], [29]. The concrete pipe lining specimen was modeled by using a commercially available finite element method (FEM) modeling software. The temperature of the concrete (geopolymer) specimen was set to $20^{\circ} \mathrm{C}$, relative permittivity is 4.5 , and the density of the concrete layer is $2300 \mathrm{~kg} / \mathrm{m}^{3}$. 


\section{B. Simulation Study}

1) Experiment 1: The aim of this experiment is to validate the developed FEM sensor model. A concrete sample having $30 \mathrm{~cm}$ (length) $\times 30 \mathrm{~cm}$ (breadth) $\times 15 \mathrm{~cm}$ (height) was modeled in the FEM software. This sample is a two resistivity layered concrete with no reinforcing bars. The $h$ is the thickness of the top resistivity layer. The apparent resistivity measurements were taken by varying the electrode spacing distance $a$ to $2.0 \mathrm{~cm}, 2.5 \mathrm{~cm}, 3.0 \mathrm{~cm}, 4.0 \mathrm{~cm}, 5.0 \mathrm{~cm}$, and 6.0 $\mathrm{cm}$ whilst varying the $h$ to $0.2 \mathrm{~cm}, 0.5 \mathrm{~cm}, 1.0 \mathrm{~cm}$, and 2.0 $\mathrm{cm}$. The experiments reported in [22], [23] were replicated in this study. The measurement results from the developed FEM sensor model were compared with the results of the previous studies.

2) Experiment 2: This experiment is to study the effects of sensor electrode contact area and two resistivity layered concrete on the apparent resistivity measurements. The concrete specimen having $50 \mathrm{~cm}$ (length) $\times 50 \mathrm{~cm}$ (breadth) $\times 2 \mathrm{~cm}$ (height) was modeled in the FEM software. Then, the apparent resistivity measurements were taken by setting the electrode contact area to $0.1 \mathrm{~cm}, 0.3 \mathrm{~cm}$ and $0.5 \mathrm{~cm}$ while varying the electrode spacing $a$ and the thickness of the top resistivity layer $h$. The resistivity of the top layer and bottom layer is $3.2 \mathrm{k} \Omega \mathrm{cm}$ and $104 \mathrm{k} \Omega \mathrm{cm}$ respectively. The values were measured by making a real sample using the concrete sewer pipe lining material. The wet resistivity was taken as the value for the top resistivity layer and reasonably cured concrete resistivity was taken for the bottom resistivity layer. The moisture was induced by using $\mathrm{pH} 7$ liquid and the measurements were taken by using a commercially available resistivity meter (Resipod, PCTE). The measured values were also used for Experiment 3.

3) Experiment 3: This experiment is to study the effects of electrode spacing and two resistivity layered concrete on the apparent resistivity measurements. Firstly, the concrete sample was modeled in the FEM simulation environment to have $50 \mathrm{~cm}$ (length) $\times 50 \mathrm{~cm}$ (breadth) $\times 2 \mathrm{~cm}$ (height). Then, the apparent resistivity measurements were taken by setting the electrode spacing distance $a$ to $0.5 \mathrm{~cm}, 1.0 \mathrm{~cm}$, $1.5 \mathrm{~cm}, 2.0 \mathrm{~cm}, 2.5 \mathrm{~cm}, 3.0 \mathrm{~cm}, 3.5 \mathrm{~cm}, 4.0 \mathrm{~cm}, 4.5 \mathrm{~cm}$, and $5.0 \mathrm{~cm}$ whilst varying the top resistivity layer thickness $h$ to $0.1 \mathrm{~cm}, 0.5 \mathrm{~cm}, 1.0 \mathrm{~cm}, 1.5 \mathrm{~cm}$, and $2.0 \mathrm{~cm}$.

4) Experiment 4: In this experiment, we study the feasibility of a machine learning approach using Gaussian Process (GP) modeling to estimate the depth of the permeation based on the apparent resistivity measurements. We assume the top resistivity layer having $3.2 \mathrm{k} \Omega \mathrm{cm}$ is an acid permeated layer. GP modeling approach [30] is employed to train a non-parametric model, which obtains apparent resistivity $\left(\rho_{a}\right)$ as inputs and predicts the acid permeated depth $(D)$. The function $f$ is learned in the form of $D=f\left(\rho_{a}\right)+\xi$, where $\xi$ is the uncertainty. Let $[X, Y]$ be the training data where $X=\left[x_{1}, x_{2}, x_{3}, \ldots \ldots, x_{m}\right]^{T}, x_{i}=\left[\left(\rho_{a}\right)_{i}\right]^{T}$, and $i(1 \leq i \leq m)$ is an integer and $m$ is the number of data pairs. $Y=\left[y_{1}, y_{2}, y_{3}, \ldots \ldots ., y_{m}\right]^{T}$ is a vector having corresponding training targets where $y_{i}=D_{i}$. $\left[X^{*}, Y^{*}\right]$ is the testing data, where $X^{*}=\left[x_{1}^{*}, x_{2}^{*}, x_{3}^{*}, \ldots \ldots, x_{n}^{*}\right]^{T}$ is a matrix having test data inputs and $Y=\left[y_{1}^{*}, y_{2}^{*}, y_{3}^{*}, \ldots \ldots, y_{n}^{*}\right]^{T}$ is a vector having predicted outputs corresponding to $X^{*}$. Once $f$ has been learned using $[X, Y], f$ can be used to predict $Y^{*}$ for a given $X^{*}$ by using $D^{*}=f\left(\rho_{a}^{*}\right)+\xi^{*}$. A $K(X, X)$ kernel having $k_{i, j}=k\left(x_{i}, x_{j}\right)$ elements was selected to address the non-linear regression problem through GP modeling. In this work, we use the squared exponential kernel, which is defined as in (2).

$$
k\left(x_{i}, x_{j}\right)=\alpha^{2} \exp \left\{-\frac{1}{2 \beta^{2}}\left\|x_{i}-x_{j}\right\|^{2}\right\}
$$

where the $\alpha$ and $\beta$ are the hyper-parameters for the GP model. The GP model was trained by minimizing the negative log marginal likelihood in (3) with respect to $\theta=\left\{\alpha, \beta, \sigma_{n}\right\}$. The covariance function $\sum$ is defined as:

$$
\begin{aligned}
-\log p(Y \mid X, \theta)= & \frac{1}{2} Y^{T}\left(\sum\right)^{-1} Y+\frac{1}{2}\left|\sum\right|+\frac{m}{2} \log (2 \pi) \\
& \sum=K(X, X)+\sigma_{n}^{2} I
\end{aligned}
$$

The GP model equations are given by (5) and (6).

$$
\begin{gathered}
(\mu)^{*}=K\left(X^{*}, X\right)\left\{K(X, X)+\sigma_{n}^{2} I\right\}^{-1} y \\
\left(\sum\right)^{*}=K\left(X^{*}, X^{*}\right)+\sigma_{n}^{2} I-\left\{K\left(X^{*}, X\right) K(X, X)+\sigma_{n}^{2} I\right\}^{-1} K\left(X, X^{*}\right)
\end{gathered}
$$

The predicted depth $\left(Y^{*}\right)$ for the testing input $\left(X^{*}\right)$ will be given by the mean of the posterior distribution $(\mu)^{*}$ and the associated uncertainty is given by the covariance $(\Sigma)^{*}$. In this experimentation, the apparent resistivity measurements were taken by keeping the electrode spacing $4 \mathrm{~cm}$ and electrode contact area as $0.3 \mathrm{~cm}$. These settings are similar to the commercially available device [31].

\section{RESULTS}

\section{A. Experiment 1: Evaluation of the Developed Sensing Model}

The four-probe FEM sensor model developed using the Wenner method was validated by comparing it with the previous scientific studies conducted by other researchers. In high humidity environments, it is assumed that the concrete close to the surface has ten times larger or smaller resistivity value than the intrinsic concrete resistivity [24]. This was simulated in the previous studies [22], [23] in two scenarios by varying the thickness of the top resistivity layer and the distance between the electrodes. In the first scenario, the top resistivity layer has $1 \mathrm{k} \Omega \mathrm{cm}$ and the bottom resistivity layer has $10 \mathrm{k} \Omega \mathrm{cm}$. This implies that the top layer has high moisture content than the bottom layer. We have modeled this scenario in simulation and apparent resistivity measurements were taken by using the developed FEM sensor model. Figure 2 shows the computed apparent resistivity measurements for the highly moist top resistivity layer. In the second scenario, we modeled the concrete 


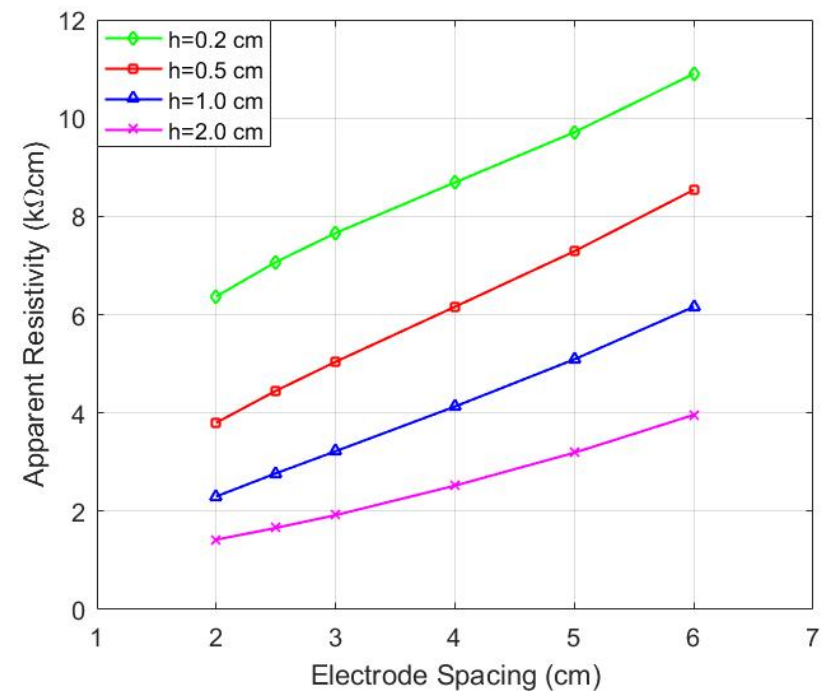

Fig. 2: Computed apparent resistivity measurements for the concrete specimen having a $1 \mathrm{k} \Omega \mathrm{cm}$ top resistivity layer and $10 \mathrm{k} \Omega \mathrm{cm}$ bottom resistivity layer.

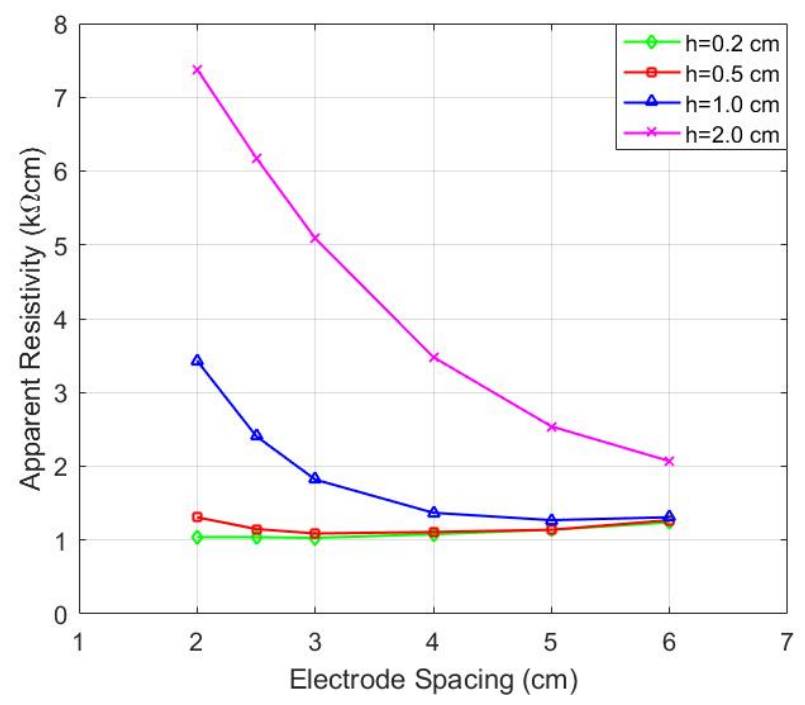

Fig. 3: Computed apparent resistivity measurements for the concrete specimen having a $10 \mathrm{k} \Omega \mathrm{cm}$ top resistivity layer and $1 \mathrm{k} \Omega \mathrm{cm}$ bottom resistivity layer.

specimen to have the top resistivity layer as $10 \mathrm{k} \Omega \mathrm{cm}$ and the bottom resistivity layer has $1 \mathrm{k} \Omega \mathrm{cm}$. This indicates that the top layer has less moisture content than the bottom layer. Figure 3 shows the computed apparent resistivity measurements for the highly moist bottom resistivity layer. The computed apparent resistivity measurements in Fig. 2 and Fig. 3 by using the developed FEM sensor model produces similar results as reported in the previous studies [22]-[24]. Hence, we will be utilising the developed FEM model for studying the effects of the electrode contact area and electrode spacing on apparent resistivity measures.
B. Experiment 2: Effects of Electrode Contact Area and Twolayered Concrete Resistivity on Apparent Resistivity Measures

When the thickness of the top resistivity layer is $1.0 \mathrm{~cm}$, $1.5 \mathrm{~cm}$, and $2.0 \mathrm{~cm}$, the apparent resistivity measurements taken for the electrode contact area of $0.1 \mathrm{~cm}, 0.3 \mathrm{~cm}$, and $0.5 \mathrm{~cm}$ showed $0.02 \mathrm{k} \Omega \mathrm{cm}$ variations when the electrode spacing is between $2.0 \mathrm{~cm}$ and $5.0 \mathrm{~cm}$. For $1.0 \mathrm{~cm}$ electrode spacing, the variations were less than $0.07 \mathrm{k} \Omega \mathrm{cm}$ for the measurements taken with the electrode contact area of 0.1 $\mathrm{cm}, 0.3 \mathrm{~cm}$, and $0.5 \mathrm{~cm}$.

For $0.5 \mathrm{~cm}$ top resistivity layer thickness, the apparent resistivity measurement variations were less than $0.08 \mathrm{k} \Omega \mathrm{cm}$ for the electrode contact area of $0.1 \mathrm{~cm}, 0.3 \mathrm{~cm}$, and 0.5 $\mathrm{cm}$ when the electrode spacing is between $2.0 \mathrm{~cm}$ and $5.0 \mathrm{~cm}$. For $1.0 \mathrm{~cm}$ electrode spacing, $0.1 \mathrm{k} \Omega \mathrm{cm}$ variation in apparent resistivity measurement was observed. For 0.1 cm top resistivity layer thickness, the apparent resistivity variations was around $0.7 \mathrm{k} \Omega \mathrm{cm}$ for the electrode contact area of $0.1 \mathrm{~cm}, 0.3 \mathrm{~cm}$, and $0.5 \mathrm{~cm}$ when the electrode spacing is between $1.0 \mathrm{~cm}$ and $5.0 \mathrm{~cm}$. Overall, from this study, it can be said that the electrode contact area has a negligible effect on apparent resistivity measurement.

C. Experiment 3: Effects of Electrode Spacing and Twolayered Concrete Resistivity on Apparent Resistivity Measures

FEM computations were performed by varying the electrode spacing and the thickness of the top concrete resistivity layer to analyse the apparent resistivity measurements on a two-layered concrete resistivity. Figure 4 shows the computed apparent resistivity values for the electrode spacing ranging from $0.5 \mathrm{~cm}$ to $5.0 \mathrm{~cm}$ and varying top concrete resistivity layer thickness ranging from $0.1 \mathrm{~cm}$ to $2.0 \mathrm{~cm}$. From the plot in Fig. 4, it can be noticed that the measurements that were taken by keeping the electrode spacing at $0.5 \mathrm{~cm}$ had the smallest apparent resistivity value whereas the measurements that were taken for the electrode spacing $5.0 \mathrm{~cm}$ had the largest resistivity value. This was noticed for the top concrete resistivity layer thickness of $0.1 \mathrm{~cm}, 0.5 \mathrm{~cm}, 1.0 \mathrm{~cm}, 1.5 \mathrm{~cm}$, and $2.0 \mathrm{~cm}$. Therefore, it can be said for the concrete sample with $2.0 \mathrm{~cm}$ thickness having two-layered concrete resistivity, there is a gradual increase in apparent resistivity measurements when there is an increase in the spacing between the electrodes.

For the electrode spacing $1.0 \mathrm{~cm}, 2.0 \mathrm{~cm}, 3.0 \mathrm{~cm}, 4.0 \mathrm{~cm}$, and $5.0 \mathrm{~cm}$, the apparent resistivity measurements for the top concrete resistivity layer having $1.5 \mathrm{~cm}$ thickness were $0.32 \mathrm{k} \Omega \mathrm{cm}, 1.25 \mathrm{k} \Omega \mathrm{cm}, 2.21 \mathrm{k} \Omega \mathrm{cm}, 3.17 \mathrm{k} \Omega \mathrm{cm}$, and 4.23 $\mathrm{k} \Omega \mathrm{cm}$ higher than the measurements taken for the top concrete resistivity layer having $2.0 \mathrm{~cm}$ thickness respectively. This shows that there are small differences in measurements between the top concrete resistivity layer having $1.5 \mathrm{~cm}$ and $2.0 \mathrm{~cm}$ thickness. Similar to previous analysis, for the electrode spacing $1.0 \mathrm{~cm}, 2.0 \mathrm{~cm}, 3.0 \mathrm{~cm}, 4.0 \mathrm{~cm}$, and $5.0 \mathrm{~cm}$, the apparent resistivity measurements for the top concrete resistivity layer having $1.0 \mathrm{~cm}$ thickness were 0.92 $\mathrm{k} \Omega \mathrm{cm}, 2.72 \mathrm{k} \Omega \mathrm{cm}, 4.41 \mathrm{k} \Omega \mathrm{cm}, 6.19 \mathrm{k} \Omega \mathrm{cm}$, and $8.23 \mathrm{k} \Omega \mathrm{cm}$ 


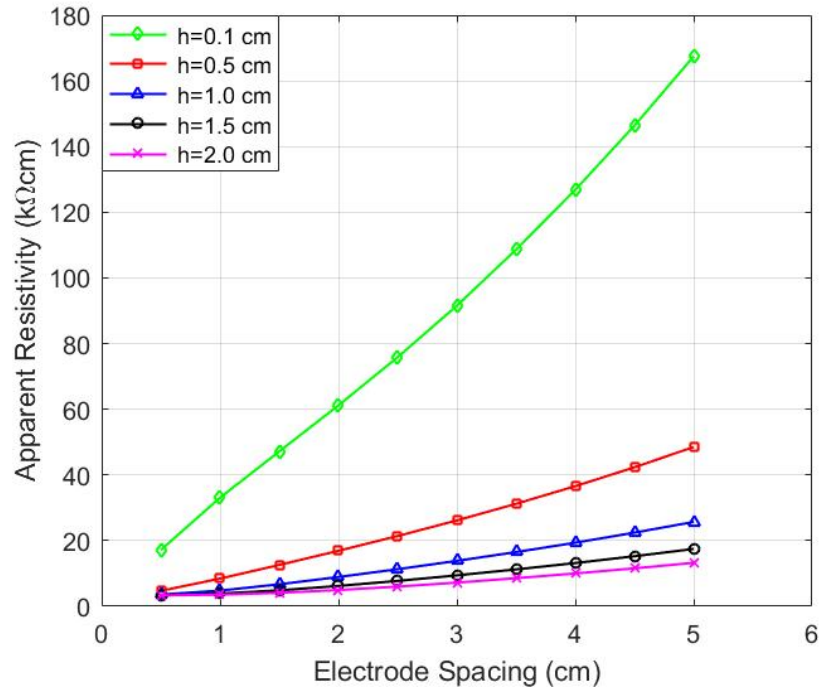

Fig. 4: Apparent resistivity measurements are taken by varying the spacing between the sensor electrodes for twolayered concrete resistivity.

higher than the measurements taken for the top concrete resistivity layer having $1.5 \mathrm{~cm}$ thickness respectively. The computed values reveal that there are no large differences in measurements between the top concrete resistivity layer having $1.0 \mathrm{~cm}$ and $1.5 \mathrm{~cm}$ thickness. Further, when the electrode spacing is $2.0 \mathrm{~cm}, 3.0 \mathrm{~cm}, 4.0 \mathrm{~cm}$, and $5.0 \mathrm{~cm}$, the relative difference in apparent resistivity measurements between the top concrete resistivity layer $1.0 \mathrm{~cm}$ and $1.5 \mathrm{~cm}$ is almost twice the relative difference in apparent resistivity measurements between the top concrete resistivity layer 1.5 $\mathrm{cm}$ and $2.0 \mathrm{~cm}$. From this analysis, we can say that there is no significantly large difference in apparent resistivity measures for all electrode spacing when the top concrete resistivity layer thickness is between 1.0 and $2.0 \mathrm{~cm}$.

When the electrode spacing is $1.0 \mathrm{~cm}, 2.0 \mathrm{~cm}, 3.0 \mathrm{~cm}, 4.0$ $\mathrm{cm}$, and $5.0 \mathrm{~cm}$, the apparent resistivity measurements for the top concrete resistivity layer having $0.5 \mathrm{~cm}$ thickness were $3.66 \mathrm{k} \Omega \mathrm{cm}, 7.98 \mathrm{k} \Omega \mathrm{cm}, 12.32 \mathrm{k} \Omega \mathrm{cm}, 17.22 \mathrm{k} \Omega \mathrm{cm}$, and $22.81 \mathrm{k} \Omega \mathrm{cm}$ higher than the measurements taken for the top concrete resistivity layer having $1.0 \mathrm{~cm}$ thickness respectively. The measured apparent resistivity values indicate that there are large differences in measurements between the top concrete resistivity layer having $0.5 \mathrm{~cm}$ and 1.0 $\mathrm{cm}$ thickness. Further, there is a significant difference in apparent resistivity measurements between the top thickness layer of $0.1 \mathrm{~cm}$ and $0.5 \mathrm{~cm}$. This shows that when the thickness of the top layer is $95 \%$ smaller compared to the sample thickness, the influence of the top layer is less in the apparent resistivity measures for the electrode spacing 3.0 $\mathrm{cm}, 4.0 \mathrm{~cm}$, and $5.0 \mathrm{~cm}$. Below $3.0 \mathrm{~cm}$ electrode spacing, the apparent resistivity measures were in between the resistivity of the top and bottom layers.

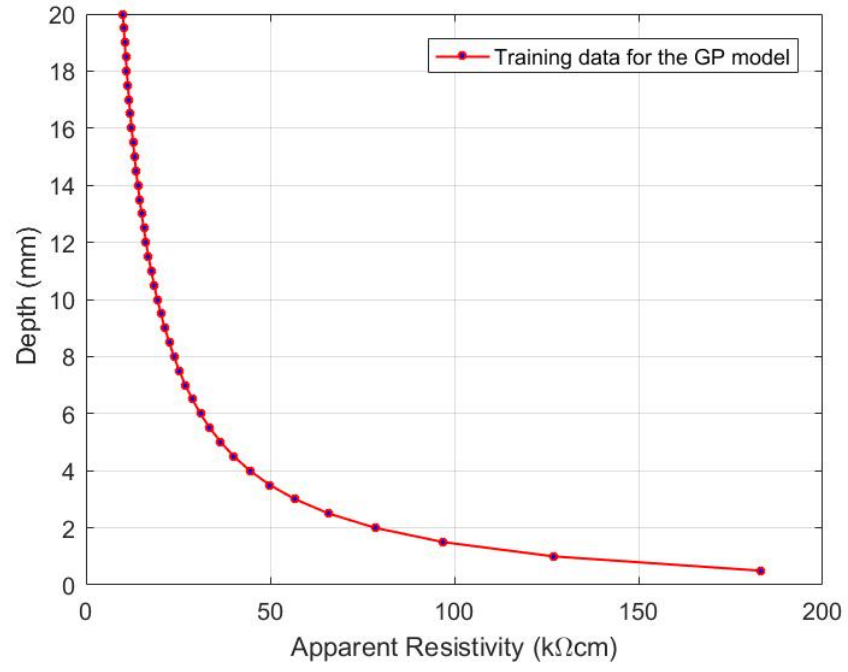

Fig. 5: Learned GP model with training data.

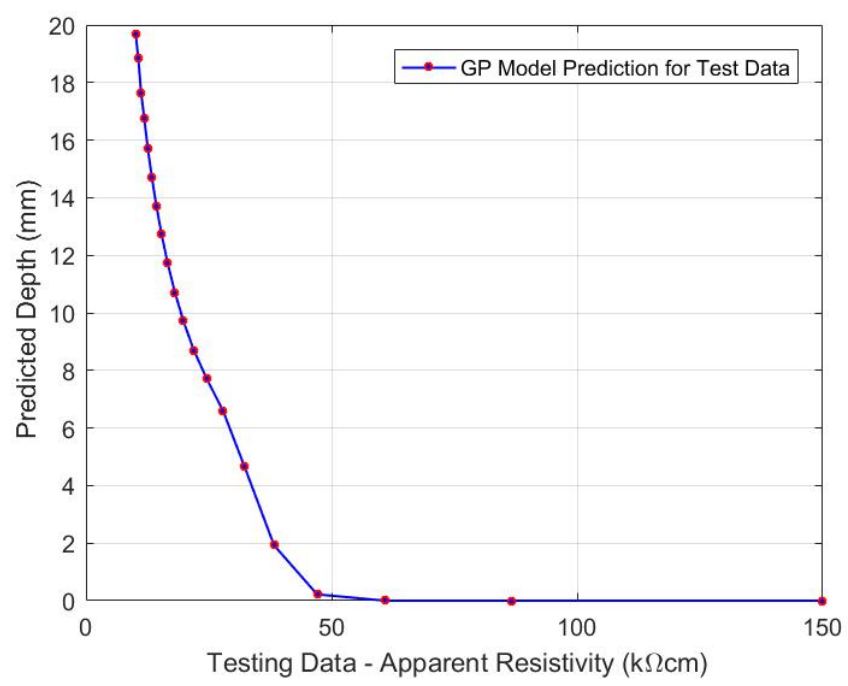

Fig. 6: GP model prediction.

\section{Experiment 4: Gaussian Process Modeling for Estimating Acid Permeation Depth}

The apparent resistivity measures obtained for different depths from the simulation study was used to train the GP model. Figure 5 shows the training data and Fig. 6 shows the predicted depth data for the test data (apparent resistivity measurements).

Figure 7 shows the behavior of GP predicted values corresponding to training data, where it can be observed that the predicted and actual depth data are similar and falls within the uncertainty bounds when the depth is 6 $\mathrm{mm}$ or more. Large uncertainty in prediction was observed when the acid permeated depth is below $6 \mathrm{~mm}$. The mean absolute error (MAE) between the actual depth and GP predicted depth is $0.67 \mathrm{~mm}$. However, predictions below the 


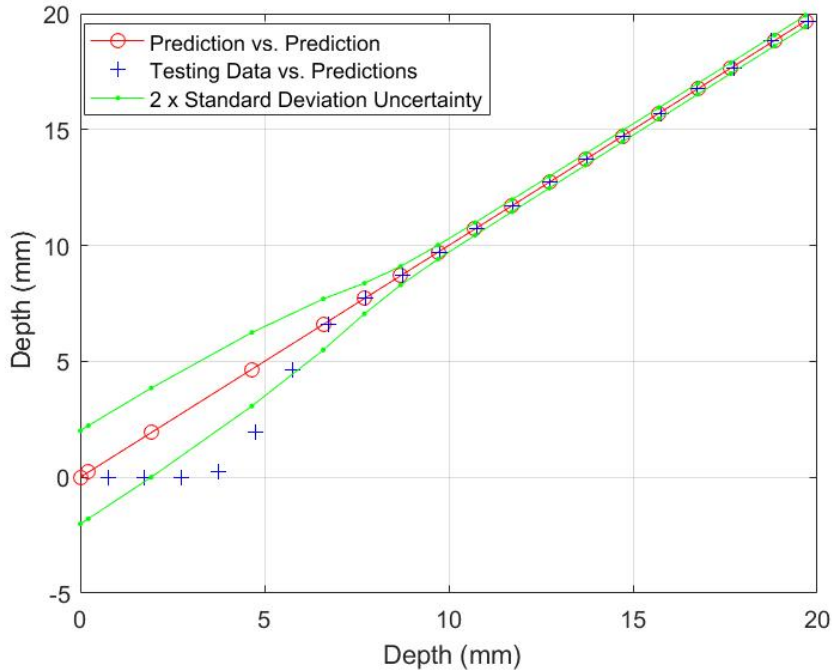

Fig. 7: The behavior of GP predicted values corresponding to training data.

depth of $6 \mathrm{~mm}$ had a MAE of $2.11 \mathrm{~mm}$. For the depth above $6 \mathrm{~mm}$, MAE was $0.05 \mathrm{~mm}$. This indicates GP predictions were reasonable for higher depth estimation.

\section{CONCLUSION AND Future WORK}

This paper studied the effects of electrode spacing and two resistivity layered concrete on apparent resistivity measurements obtained by using the four-probe Wenner method. The following summarizes the key outcomes.

- A FEM based four-probe Wenner array model was developed for measuring apparent resistivity on a concrete block. The developed model was evaluated with similar studies available in the literature. The outcome of the evaluation was similar to previous studies. Hence, the developed sensor model was utilized for measuring apparent resistivity in this study.

- The sensor measurements were taken by setting the electrode contact area as $0.1 \mathrm{~cm}, 0.3 \mathrm{~cm}$, and $0.5 \mathrm{~cm}$. It was observed that the electrode contact area had negligible effects on apparent resistivity measurements.

- For the thickness of the top resistivity layer from 0.1 $\mathrm{cm}$ to $2.0 \mathrm{~cm}$, an increase in apparent resistivity measurements was observed when the electrode spacing increased from $0.5 \mathrm{~cm}$ to $5.0 \mathrm{~cm}$.

- Smaller the electrode spacing i.e., $0.5 \mathrm{~cm}$, the apparent resistivity measurement values were smaller compared to measurements taken at larger electrode spacing distance. On the contrary, larger apparent resistivity measurement values were observed when the electrode spacing is larger, i.e., $5.0 \mathrm{~cm}$.

- A significant increase in apparent resistivity measurements was observed when the thickness of the top resistivity layer is less than $0.5 \mathrm{~cm}$. When the top resistivity layer thickness is more than $1.0 \mathrm{~cm}$, smaller variations in apparent resistivity were observed.

- A Gaussian process based model was formulated to estimate the depth of acid permeation. The depth predictions were reasonably good when the acid permeated layer thickness is more than $0.6 \mathrm{~cm}$.

In the future, we intend to extend the reported work by studying the combined effects of electrode spacing and two resistivity layered concrete on apparent resistivity measurements by using real concrete samples. The two-layered resistivity of the concrete sample will be created by exposing the sample to an aqueous solution having different $\mathrm{pH}$ values. Laboratory experimental results will be compared with the simulation results for further investigations.

\section{ACKNOWLEDGMENT}

This paper is an outcome from the Smart Linings for Pipes and Infrastructure project funded by the Australian Federal Government through the Cooperative Research Centres Projects (CRC-P) grant. The CRC-P Program supports industry-led collaborations between industry, researchers and the community. This CRC-P program is led by the Water Services Association of Australia in collaboration with 34 collaborative partners including researchers, water utilities and industry partners. The reported work is a part of the sub-project 3 on Smart Sensing led by the University of Technology Sydney. The sub-project 3 partners are Abergeldie Watertech Pty Ltd, Bisley Company Pty Ltd, Calucem, Central SEQ Distributor-Retailer Authority (Queensland Urban Utilities), Downer Pty Ltd, Insituform Pacific Pty Ltd (Aegion), Interflow Pty Ltd, Milliken Infrastructure Solutions LLC, Parchem Construction Supplies Pty Ltd, Sanexen Environmental Services, South Australian Water Corporation, South East Water Corporation, Sydney Water Corporation, University of Technology Sydney, Ventia Pty Ltd, Water Corporation and Water Services Association of Australia.

\section{REFERENCES}

[1] T. Wells and R. E. Melchers, "An observation-based model for corrosion of concrete sewers under aggressive conditions," Cement and Concrete Research, vol. 61, pp. 1-10, 2014.

[2] M. Quintero-Núñez, B. Valdez, and M. Schorr, "Effect of H2S on corrosion in polluted waters," in Advanced Materials Research, vol. 95. Trans Tech Publ, 2010, pp. 33-36.

[3] K. Thiyagarajan and S. Kodagoda, "SMART monitoring of surface temperature and moisture content using multisensory data fusion," in 2015 IEEE 7th International Conference on Cybernetics and Intelligent Systems (CIS) and IEEE Conference on Robotics, Automation and Mechatronics (RAM), 2015, pp. 222-227.

[4] M. Ams, P. Giri, P. Dekker, S. Taheri, J. Gonzalez, S. Clark, T. Kuen, L. Vorreiter, H. Bustamante, and M. J. Withford, "Optical Fibre Sensors for Monitoring Sewer Concrete Corrosion," in The European Conference on Lasers and Electro-Optics 2019. Munich: Optical Society of America, 2019.

[5] N. Stanić, C. d. Haan, M. Tirion, J. Langeveld, and F. H. L. R. Clemens, "Comparison of core sampling and visual inspection for assessment of concrete sewer pipe condition," vol. 67, no. 11, pp. 2458-2466, 2013. 
[6] B. Li, X. Fan, J. Zhang, Y. Wang, F. Chen, S. Kodagoda, T. Wells, L. Vorreiter, D. Vitanage, G. Iori, D. Cunningham, and T. Chen, "Predictive Analytics Toolkit for H2S Estimation and Sewer Corrosion," in OZWater. Sydney: Australian Water Association, 2017.

[7] Y. Liu, K. R. Sharma, S. Murthy, I. Johnson, T. Evans, and Z. Yuan, "On-line monitoring of methane in sewer air," Scientific reports, vol. 4, 2014.

[8] K. Thiyagarajan, S. Kodagoda, R. Ranasinghe, D. Vitanage, and G. Iori, "Robust sensing suite for measuring temporal dynamics of surface temperature in sewers," Scientific Reports, vol. 8, no. 1, p. 16020, 2018. [Online]. Available: http://www.nature.com/articles/ s41598-018-34121-3

[9] K. Thiyagarajan, S. Kodagoda, and J. K. Alvarez, "An instrumentation system for smart monitoring of surface temperature," in 2016 14th International Conference on Control, Automation, Robotics and Vision (ICARCV), 2016, pp. 1-6.

[10] K. Thiyagarajan, S. Kodagoda, R. Ranasinghe, G. Iori, and D. Vitanage, "Robust Sensor Suite Combined with Predictive Analytics Enabled Anomaly Detection Model for Smart Monitoring of Concrete Sewer Pipe Surface Moisture Conditions,” IEEE Sensors Journal, 2020.

[11] K. Thiyagarajan, "Robust Sensor Technologies Combined with Smart Predictive Analytics for Hostile Sewer Infrastructures,” Ph.D. dissertation, University of Technology Sydney, 2018.

[12] K. Thiyagarajan, S. Kodagoda, L. V. Nguyen, and R. Ranasinghe, "Sensor Failure Detection and Faulty Data Accommodation Approach for Instrumented Wastewater Infrastructures,” IEEE Access, vol. 6, pp 56562-56574, 2018.

[13] K. Thiyagarajan, S. Kodagoda, and L. Nguyen, "Predictive Analytics for Detecting Sensor Failure Using Autoregressive Integrated Moving Average Model," in 12th IEEE Conference on Industrial Electronics and Applications. Siem Reap: IEEE, 2017, pp. 1923-1928.

[14] N. Ulapane, L. Piyathilaka, and S. Kodagoda, "Some Convolution and Scale Transformation Techniques to Enhance GPR Images," in 2019 14th IEEE Conference on Industrial Electronics and Applications (ICIEA). IEEE, 2019, pp. 1453-1458.

[15] L. Piyathilaka, B. Sooriyaarachchi, S. Kodagoda, and K. Thiyagarajan, "Capacitive Sensor Based 2D Subsurface Imaging Technology for Non Destructive Evaluation of Building Surfaces," in 2019 IEEE 9th international conference on cybernetics and intelligent systems (CIS) and IEEE conference on robotics, automation and mechatronics (RAM). IEEE, 2019.

[16] K. Thiyagarajan, S. Kodagoda, L. V. Nguyen, and S. Wickramanayake, "Gaussian Markov Random Fields for Localizing Reinforcing Bars in Concrete Infrastructure," in 2018 Proceedings of the 35th International Symposium on Automation and Robotics in Construction. Berlin: IAARC, 2018, pp. 1052-1058.

[17] S. Wickramanayake, K. Thiyagarajan, S. Kodagoda, and L. Piyathilaka, "Frequency Sweep Based Sensing Technology for Non-destructive Electrical Resistivity Measurement of Concrete," in 2019 Proceedings of the 36th ISARC. IAARC, 2019, pp. 1290-1297.

[18] N. Ulapane, S. Wickramanayake, and S. Kodagoda, "Pulsed Eddy Current Sensing for Condition Assessment of Reinforced Concrete," in 2019 14th IEEE Conference on Industrial Electronics and Applications (ICIEA). IEEE, 2019, pp. 1-6.

[19] N. Giovanangeli, L. Piyathilaka, S. Kodagoda, K. Thiyagarajan, S. Barclay, and D. Vitanage, "Design and development of drill-resistance sensor technology for accurately measuring microbiologically corroded concrete depths," in Proceedings of the 36th International Symposium on Automation and Robotics in Construction. IAARC, 2019, pp. 735-742.

[20] L. Zhang, P. De Schryver, B. De Gusseme, W. De Muynck, N. Boon, and W. Verstraete, "Chemical and biological technologies for hydrogen sulfide emission control in sewer systems: a review," Water research, vol. 42, no. 1, pp. 1-12, 2008.

[21] D. Mishra and A. Shalivahan, "Sensitivity Plots Using COMSOL 5.1 Multiphysics; A Tool for Optimizing Geophysical Field Survey," in Proceedings of 2015 COMSOL Conference, Pune, 2015.

[22] S. Millard and K. Gowers, "Influence of surface layers upon the measurement of concrete resistivity," ACI Special Publ, vol. 126, pp. 1197-1221, 1991.

[23] F. Presuel-Moreno, Y. Liu, and M. Paredes, "Understanding the Effect of Rebar Presence and/or Multilayered concrete resistivity on the apparent surface resistivity measured via the four-point wenner method," in Corrosion 2009. Atlanta: NACE International, 2009.
[24] F. Presuel-Moreno, Y. Liu, and Y. Y. Wu, "Numerical modeling of the effects of rebar presence and/or multilayered concrete resistivity on the apparent resistivity measured via the Wenner method," Construction and Building Materials, vol. 48, pp. 16-25, 2013.

[25] G. F. Tagg, Earth Resistances. London: George Newnes Limited, 1964.

[26] K. Thiyagarajan, S. Kodagoda, and N. Ulapane, "Data-driven machine learning approach for predicting volumetric moisture content of concrete using resistance sensor measurements," in 2016 IEEE 11th Conference on Industrial Electronics and Applications (ICIEA), 2016, pp. 1288-1293.

[27] K. Thiyagarajan and S. Kodagoda, "Analytical Model and Data-driven Approach for Concrete Moisture Prediction," in 33rd International Symposium on Automation and Robotics in Construction (ISARC 2016). Auburn: IAARC, 2016, pp. 298-306.

[28] S. G. Millard and K. R. Gowers, "Resistivity assessment of in-situ concrete: The influence of conductive and resistive surface layers," Proceedings of the Institution of Civil Engineers: Structures and Buildings, pp. 389-396, 1992.

[29] R. J. Kessler, R. G. Powers, and M. A. Paredes, "Resistivity measurements of water saturated concrete as an indicator of permeability," in NACE - International Corrosion Conference Series. Houston: NACE International, 2005.

[30] C. E. Rasmussen, “Gaussian processes for machine learning," 2006.

[31] "Resipod-Resistivity Meter," p. 3. [Online]. Available: http://www. pcte.com.au/images/pdf/Resipod-ResistivityMeter/Resipod.pdf 